BMJ Open Sport \& Exercise Medicine

\title{
Long-term effects of daily physical education throughout compulsory school on duration of physical activity in young adulthood: an 11-year prospective controlled study
}

Amanda Lahti, Björn E Rosengren, Jan-Åke Nilsson, Caroline Karlsson, Magnus K Karlsson Nilsson J-Å, et al. Longterm effects of daily physical education throughout compulsory school on duration of physical activity in young adulthood: an 11-year prospective controlled study. BMJ Open Sport \& Exercise Medicine 2018;4:e000360. doi:10.1136/ bmjsem-2018-000360

- Additional material is published online only. To view please visit the journal online (http://dx.doi.org/10.1136/ bmjsem-2018-000360).

Accepted 15 March 2018
To cite: Lahti A, Rosengren BE,

\section{ABSTRACT}

Objectives We examined whether daily physical activity (PA) during compulsory school encourages children to be more physically active during the intervention and 4 years after termination of the programme.

Methods This prospective controlled intervention study followed the same 124 children (81 children in an intervention group and 43 controls) aged $7.7 \pm 0.6$ (mean \pm SD) during a 7-year PA intervention and 4 years after the intervention when the children were $18.7 \pm 0.3$ years old. The intervention included daily school physical education (PE) (200 min/week), whereas the controls continued with the Swedish standard of $60 \mathrm{~min} /$ week. Using a questionnaire, we gathered data about total PA, leisure time PA and sedentary activities (SA). Group comparisons are adjusted for age and gender, and data are provided as means with $95 \%$ Cls.

Results At baseline, we found similar duration of PA and SA between groups. After a mean of 7 years with intervention, the intervention group was more physically active than the controls (+4.5 (2.9 to 6.0) hours/week), whereas SA was similar ( +0.6 ( -2.5 to 3.9$)$ hours/week). Four years beyond the intervention, the intervention group was still more physically active than the controls (2.7 (0.8 to 4.7) hours/week), and SA was still similar (-3.9 (-9.7 to 1.7) hours/week).

Conclusions Intervention with daily school PE throughout compulsory school is associated with higher duration of PA not only during the intervention but also 4 years after termination of the programme.

\section{INTRODUCTION}

Clinical and Molecular Osteoporosis Research Unit, Department of Orthopedics and Clinical Sciences, Lund University, Skåne University Hospital, Malmö, Sweden

Correspondence to Dr Amanda Lahti; amanda. lahti@med.lu.se
Physical activity (PA) is in children associated with health benefits, ${ }^{1}$ including outcomes related to bone and muscle, ${ }^{2}$ body weight, ${ }^{3}$ academic achievement, ${ }^{4}$ and reduced risk of developing obesity, type II diabetes and hypertension. ${ }^{5}$ The guidelines of the WHO recommend children aged 5-17 years to take part in at least 60 min of PA per day. ${ }^{6}$ However, only $20 \%$ of global $13-15$ year olds meet these

\section{What are the new findings?}

- An intervention programme with daily physical education throughout compulsory school is followed by higher duration of physical activity during the programme but also 4 years beyond termination of the intervention (11 years after baseline).

- These results were found with an intervention that was given within the compulsory national school curriculum, without extra resources and extra personnel or incremental costs, with guidance by the regular teachers, making it possible to apply to all schools.

- Contradictory to the Activity Stat Theory, children do not compensate increased duration of physical activity with increased sedentary behaviour.

- These findings are of importance since it seems possible to teach children an active lifestyle with maintained effects in young adulthood, and that this method could possibly be effective to prevent inactivity-related diseases later in life.

recommendations ${ }^{7}$ and physical education (PE) in schools is decreasing. ${ }^{8} \mathrm{PE}$ interventions have the potential to reverse these trends since schools reach almost all children. ${ }^{8}$

Most previous PA intervention studies have shown effective results on PA levels during the programme. ${ }^{9-11}$ But few have focused on what happens with the activity levels after the programme, and the results from these studies are conflicting. ${ }^{12-17}$ Further, studies that suggest that there is an association between PA levels in childhood and adulthood have only evaluated voluntary PA levels, ${ }^{18} 19$ but not if increased PA levels by interventions are maintained in young adulthood or not. Even more, the Activity Stat Theory suggests that the level of PA in children is centrally regulated to a predefined level, specific for every child, ${ }^{20-22}$ and that all attempts to increase PA 
would be counteracted by a compensatory decline in PA during other parts of the day.

We therefore aimed to examine whether a schoolbased PA intervention throughout compulsory school induces a more physically active lifestyle that remains 4 years after the intervention, when the children reached young adulthood.

\section{MATERIALS AND METHODS}

The Pediatric Osteoporosis Prevention study is a prospective controlled intervention study where four neighbouring, government-funded elementary schools were invited to participate. One school was chosen as intervention school and three as control schools. Children were allocated to schools according to their residential address. PE is a mandatory school subject in Sweden, all children had to participate. Before we initiated intervention, all schools had the Swedish standard $\mathrm{PE}$ curriculum of $60 \mathrm{~min}$ in one or two classes per week.
The intervention school increased duration of PE from $60 \mathrm{~min} /$ week to $200 \mathrm{~min} /$ week (40 min PE per school day). The intervention included activities of the regular curriculum and were led by the same teachers as before the start of the study. The control schools continued with the Swedish standard PE curriculum.

At baseline we invited all children who started first or second grade between 1999 and 2000 to participate in the study. There were $192 / 302$ boys and $157 / 262$ girls who accepted participation (figure 1). At baseline the participants were $7.7 \pm 0.6$ years old $($ mean $\pm \mathrm{SD})$ and $98 \%$ were of Caucasian ethnicity. The children were annually re-evaluated with questionnaire, physical performance tests and physical measurements during the intervention and $3.7 \pm 0.5$ years after termination. In this report, we present the re-evaluations after $5.0 \pm 0.1$ and $7.4 \pm 0.6$ years during the intervention period and the follow-up visit 4 years beyond the programme. In Sweden, compulsory school last for 9 years but since the children started

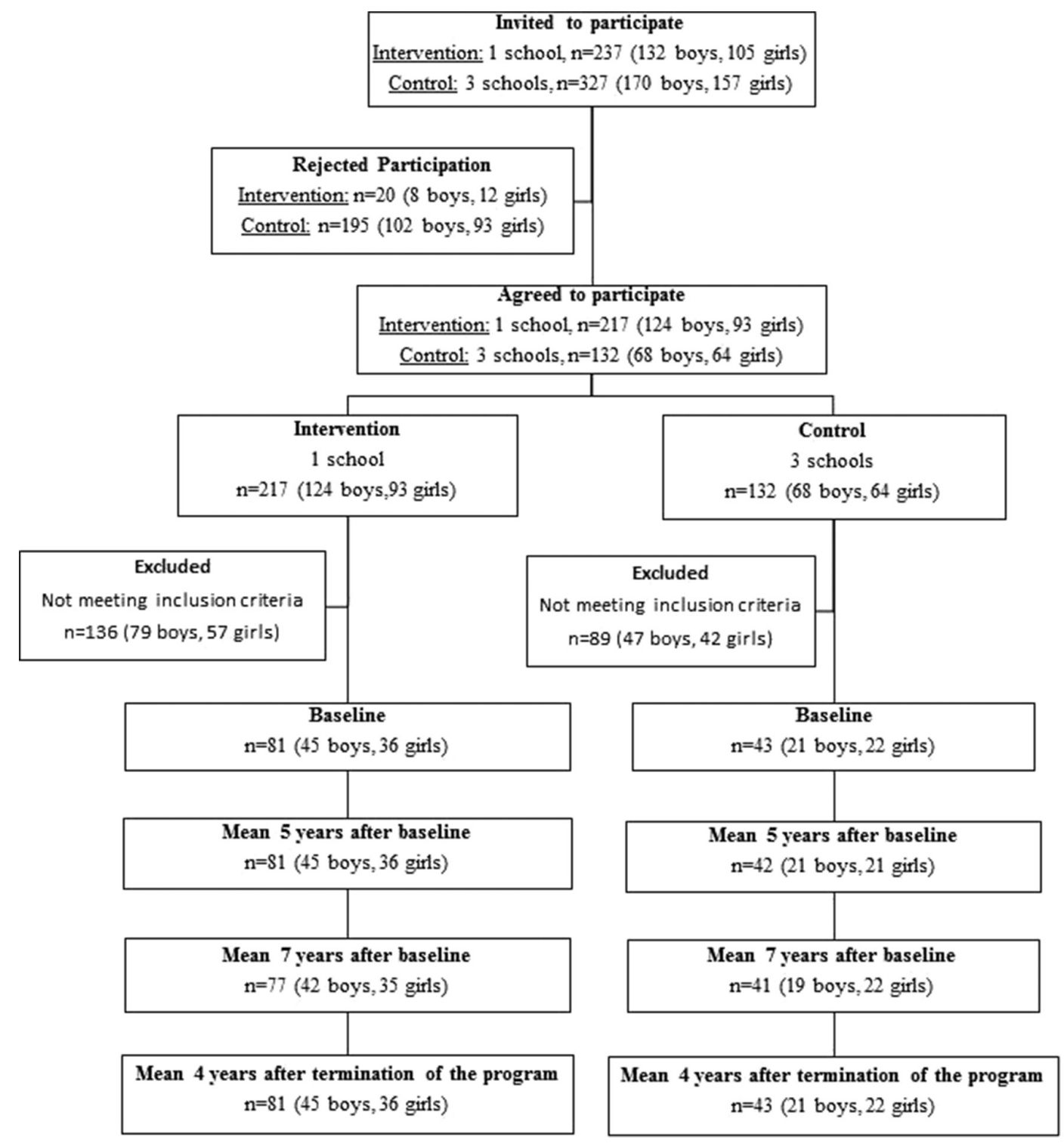

Figure 1 A flow-chart of the study-population 
Table 1 Anthropometric measurements and lifestyle factors in the intervention group and control group

\begin{tabular}{|c|c|c|c|c|}
\hline & \multicolumn{2}{|l|}{ Intervention } & \multicolumn{2}{|l|}{ Control } \\
\hline & Boys & Girls & Boys & Girls \\
\hline \multicolumn{5}{|l|}{ Baseline } \\
\hline Caucasian (\%) & $45(100)$ & $36(100)$ & $19(90.5)$ & $22(100)$ \\
\hline Age (years) & $7.5 \pm 0.6$ & $7.5 \pm 0.6$ & $8.0 \pm 0.7$ & $7.9 \pm 0.6$ \\
\hline Weight (kg) & $27.8 \pm 5.5$ & $26.5 \pm 5.3$ & $27.4 \pm 4.5$ & $27.0 \pm 6.1$ \\
\hline BMI $\left(\mathrm{kg} / \mathrm{m}^{2}\right)$ & $16.7 \pm 2.5$ & $16.5 \pm 2.5$ & $16.1 \pm 1.5$ & $16.2 \pm 2.1$ \\
\hline \multicolumn{5}{|c|}{ Mean $5.0 \pm 0.6($ mean $\pm S D)$ years after baseline } \\
\hline Age (years) & $12.6 \pm 0.6$ & $12.5 \pm 0.6$ & $12.9 \pm 0.7$ & $12.9 \pm 0.6$ \\
\hline Height (cm) & $158.0 \pm 10.5$ & $158.6 \pm 8.6$ & $159.7 \pm 9.5$ & $158.5 \pm 8.1$ \\
\hline \multicolumn{5}{|c|}{ Mean $7.4 \pm 0.6($ mean $\pm S D)$ years after baseline } \\
\hline Age (years) & $15.0 \pm 0.5$ & $15.1 \pm 0.6$ & $15.3 \pm 0.5$ & $15.0 \pm 0.8$ \\
\hline Height (cm) & $175.0 \pm 9.1$ & $166.9 \pm 5.6$ & $175.1 \pm 9.3$ & $164.9 \pm 5.5$ \\
\hline Weight (kg) & $64.8 \pm 13.8$ & $57.9 \pm 7.7$ & $62.7 \pm 11.3$ & $54.3 \pm 9.7$ \\
\hline BMI $\left(\mathrm{kg} / \mathrm{m}^{2}\right)$ & $21.1 \pm 3.9$ & $20.8 \pm 2.4$ & $20.4 \pm 2.8$ & $19.9 \pm 2.5$ \\
\hline Tanner stage $1 / 2 / 3 / 4 / 5(\%)$ & $0 / 0 / 3 / 23 / 74$ & 0/0/12/39/49 & 0/0/0/18/82 & $0 / 0 / 0 / 54 / 46$ \\
\hline \multicolumn{5}{|c|}{ Mean $3.7 \pm 0.5($ mean $\pm S D)$ years after termination of intervention } \\
\hline Age (years) & $18.7 \pm 0.2$ & $18.7 \pm 0.4$ & $18.8 \pm 0.3$ & $18.7 \pm 0.3$ \\
\hline
\end{tabular}

BMI, body mass index.

the intervention in first or second grade, the mean duration of intervention was $7.4 \pm 0.6$ in our study-cohort. At the last follow-up $3.7 \pm 0.5$ years after termination of the intervention, 66 boys and 58 girls attended and were then aged $18.7 \pm 0.3$ years. To be included in this report, children had to have participated in the baseline and the last follow-up exams (figure 1).

We measured height $(\mathrm{cm})$ and weight $(\mathrm{kg})$ by standard equipment (Holtain Stadiometer and Avery Berkel HL 120 electric scale). Our research nurses assessed Tanner stage $^{2324}$ at baseline, while self-assessment was used thereafter and reported in the questionnaire. We registered organised PA during leisure time (ie, mean value of weekly summer and winter leisure time PA) and duration of sedentary activities (SA), defined as screen time activities by a questionnaire. ${ }^{25}{ }^{26} \mathrm{SA}$ was in the questionnaire answered in hours/day but converted to hours/week in this study. Total PA was estimated as the summarized duration of school PE and leisure time PA.

At the last follow-up the questionnaire was modified and the total PA was assessed as (1) weekly duration of PA (except walking) and (2) weekly duration of walking as exercise, also in summer and winter separately. If PA was only reported in one season, we used this as the annual duration of PA. Missing values in both seasons were excluded from the analysis. Reported weekly kilometres of walking as exercise were translated to duration by use of a walking speed of $6 \mathrm{~km} /$ hour. SA at the last follow-up also included book reading, crossword puzzle solving and time spent in vehicles. Annual mean PA was estimated as previously. Even if the questionnaires are not validated, they have been used in previous published reports. ${ }^{292526}$ Questions regarding PA and SA from the questionnaires are found in online supplementary appendix 1 .

Dropout analysis revealed no significant differences in anthropometrics, PA and SA at baseline and at the last intervention evaluation between children included in this report and those who did not fulfil the inclusion criteria (data not shown). We have previously found similar anthropometrics in the children who attended the baseline exam with those who did not by use of the Swedish compulsory first-grade school health examinations. ${ }^{25}$ 
Table 2 Duration of PA and sedentary behaviour in hours/week during mean 7.4 years with daily school PA in the intervention group and 1-2 days/week in the control group and mean 3.7 years after termination of the intervention

\begin{tabular}{|c|c|c|c|c|}
\hline & $\begin{array}{l}\text { Intervention } \\
\text { (unadjusted values) } \\
\text { ( } \mathrm{n=81} \text { ) }\end{array}$ & $\begin{array}{l}\text { Control } \\
\text { (unadjusted values) } \\
(n=43)\end{array}$ & $\begin{array}{l}\text { Mean difference } \\
\text { (group comparison } \\
\text { adjusted for gender } \\
\text { and age) }\end{array}$ & $\begin{array}{l}\text { P values } \\
\text { (group comparison } \\
\text { adjusted for gender } \\
\text { and age) }\end{array}$ \\
\hline \multicolumn{5}{|l|}{ Just before baseline } \\
\hline PA in leisure time & 2.7 (2.0 to 3.3 ) & $3.0(2.1$ to 3.8$)$ & $-0.2(-1.2$ to 0.8$)$ & 0.69 \\
\hline Sedentary activity & 12.5 (11.1 to 13.9$)$ & 11.4 (10.1 to 12.8$)$ & $1.7(-0.4$ to 3.9$)$ & 0.13 \\
\hline \multicolumn{5}{|l|}{ Baseline } \\
\hline PE in school & 3.3 & 1.0 & Not applicable & Not applicable \\
\hline PA in leisure time & 2.7 (2.0 to 3.3 ) & $3.0(2.1$ to 3.8$)$ & $-0.2(-1.2$ to 0.8$)$ & 0.69 \\
\hline Total PA & 6.0 (5.3 to 6.6$)$ & 4.0 (3.1 to 4.8$)$ & $2.1(1.1$ to 3.1$)$ & $<0.001$ \\
\hline Sedentary activity & 12.5 (11.1 to 13.9$)$ & 11.4 (10.1 to 12.8$)$ & $1.7(-0.4$ to 3.9$)$ & 0.13 \\
\hline \multicolumn{5}{|c|}{$5.0 \pm 0.6($ mean $\pm S D)$ years after baseline } \\
\hline PE in school & 3.3 & 1.0 & Not applicable & Not applicable \\
\hline PA in leisure time & $6.1(5.1$ to 7.1$)$ & 5.0 (4.0 to 6.0$)$ & $1.2(-0.2$ to 2.6$)$ & 0.10 \\
\hline Total PA & $9.4(8.4$ to 10.4$)$ & $6.0(5.0$ to 7.0$)$ & 3.5 (2.1 to 4.9$)$ & $<0.001$ \\
\hline Sedentary activity & 15.9 (14.5 to 17.3$)$ & 18.7 (16.0 to 21.3$)$ & $-2.3(-5.1$ to 0.5$)$ & 0.11 \\
\hline \multicolumn{5}{|c|}{$7.4 \pm 0.6($ mean $\pm S D)$ years after baseline } \\
\hline PE in school & 3.3 & 1.0 & Not applicable & Not applicable \\
\hline PA in leisure time & 6.7 (5.5 to 7.9$)$ & 4.4 (3.3 to 5.6$)$ & 2.1 (0.6 to 3.6$)$ & $<0.01$ \\
\hline Total PA & 10.0 (8.8 to 11.2$)$ & 5.4 (4.3 to 6.5$)$ & 4.5 (2.9 to 6.0$)$ & $<0.001$ \\
\hline Sedentary activity & 19.5 (17.2 to 21.7$)$ & $18.6(16.0$ to 21.1$)$ & $0.6(-2.5$ to 3.9$)$ & 0.71 \\
\hline \multicolumn{5}{|c|}{$3.7 \pm 0.5($ mean $\pm S D)$ years after termination of intervention } \\
\hline PA besides walking & $5.8(4.5$ to 7.1$)$ & 3.7 (2.7 to 4.6$)$ & 2.1 (0.5 to 3.7$)$ & $<0.05$ \\
\hline Duration of walking & $1.6(1.0$ to 2.2$)$ & $1.0(0.2$ to 1.7$)$ & $0.7(-0.2$ to 1.5$)$ & 0.15 \\
\hline Total PA & $7.4(5.9$ to 8.9$)$ & 4.7 (3.4 to 5.9$)$ & 2.7 (0.8 to 4.7$)$ & $<0.01$ \\
\hline Sedentary activity & 23.5 (20.6 to 26.4 ) & 27.1 (22.0 to 32.2) & $-3.9(-9.7$ to 1.7$)$ & 0.19 \\
\hline
\end{tabular}

Data are presented as mean and $95 \% \mathrm{Cl}$ (bootstrapped $\mathrm{Cl}$ ) within brackets.

Statistically significant differences are highlighted in bold.

PA, physical activity; PE, physical education.

We used IBM SPSS (V.23); descriptive statistics are presented as numbers (n), proportions (\%) and mean $\pm \mathrm{SD}$, and inferential statistics as means with $95 \%$ CIs. Shapiro-Wilk test was used to test normality distribution of the data. Differences between groups were tested by Student's t-test, $\chi^{2}$ test or univariate bootstrapped 10000 samples analysis of covariance (adjusted for age and gender). $\mathrm{P}<0.05$ was considered a statistically significant difference.

\section{RESULTS}

Descriptive statistics of the study cohort are presented in table 1. Throughout the 7-year intervention, the children in the intervention group were more physically active than their counterparts in the control group $(p<0.001$ for all evaluated periods). After 7 years of intervention, the children also participated in more leisure time PA $(p<0.01)$. No significant difference in duration of SA was found between the intervention and control children throughout the intervention period (table 2).
Four years after termination of the programme, children who previously received intervention were more physically active than those who did not $(\mathrm{p}<0.01)$ (table 2), while SA was still non-significant (table 2).

\section{DISCUSSION}

In this prospective controlled study, we found that daily PE intervention throughout compulsory school encourages a more physically active lifestyle in children who remain after the programme into young adulthood. Therefore, extra school PE seems to be a possible strategy to increase PA in children with maintained effects beyond the programme. With these results, we speculate that daily school PE may be one strategy to prevent inactivity-related diseases later in life.

Most previous studies have focused on short-term effects of PA interventions (ie, 1-3 years of an intervention), ${ }^{9-11}$ and the few studies that have focused on possible long-term effects (ie, 1-2 years after the intervention) are conflicting. ${ }^{12-17}$ Further, the studies that 
suggest that there is an association between PA levels in childhood and adulthood have only evaluated voluntary PA levels. Whether an intervention programme in young years could influence the 'tracking' has, to our knowledge, never been evaluated in studies with a prospective controlled study design. This study increases our knowledge when reporting that a PE intervention programme during growth has benefits in PA activity level that remain at least 4 years after the intervention.

Contradictory to the Activity Stat Theory, we found that children's PA habits are modifiable and not set at an intrinsic level. ${ }^{20-22}$ Furthermore, we found that children exposed to daily school PE had almost mean 4 hours less of SA per week than children in the control group. This difference was not statistically significant, but still of such interest that it should be explored in future studies, since inactivity, irrespective of the amount of PA, is associated to adverse health outcomes. ${ }^{27}$

Study strengths include the long follow-up and the prospective controlled study design within a defined geographical area with a homogeneous population. Another benefit is that the intervention was given within the compulsory national school curriculum, without extra resources, extra personnel or incremental costs, with guidance by the regular teachers. It is also important to mention that even if the questionnaire was modified at the last follow-up, it is still possible to make a cross-sectional comparison between the two groups at each separate evaluation, even if it limits the possibility to evaluate changes in PA and SA longitudinally.

Weaknesses include the non-randomised design (which makes causal inferences impossible) and the relatively small sample size. There is a risk of confounding since other factors (eg, influence from parents and friends, living conditions and the child's internal beliefs) are also associated with duration of PA in children. ${ }^{28}$ We would also have preferred registration of quality and intensity of PA. The well-described difficulties to estimate PA in children are another concern, ${ }^{29}$ and we would have preferred to use a validated PA questionnaire and objective measurements of PA. Further, our findings must be verified in other ethnic and socioeconomic groups.

In summary, an intervention with daily PE throughout compulsory school is associated with higher duration of PA also beyond the programme in young adulthood. In the same way that we teach our children to brush their teeth which they continue with throughout life, we can also teach them a physically active lifestyle that follows to young adulthood by implementing daily PA in school.

Contributors AL: provided extensive work on cleaning, analysing and interpreting the data; and drafted and revised the paper. BER: contributed to interpretation of data for the work; revised it critically and provided important intellectual content; and provided final approval of the version to be published. J-ÅN: substantial contributions to the statistical design and analysis used in this work; revised the work and provided valuable, intellectual important content; and provided final approval of the version to be published. CK: collected the data and contributed to the interpretation of the work and revised it for final approval. MKK: collection of data and substantial contributions to gaining, analysis and interpretation of the data of the work and revising the draft several times, and provided intellectual content to it. All authors have given an agreement to be accountable for all aspects of the work in ensuring that questions related to the accuracy or integrity of any part of the work are appropriately investigated and resolved.

Funding Financial support was received from the Centre for Athletic Research, Skåne Regional Foundations, ALF Foundations and FoUU Foundations.

Competing interests None declared.

Patient consent Parental/guardian consent obtained.

Ethical approval The study was approved by the Ethics Committee of Lund University, Sweden (LU 453-98; 1998-09-15), registered as clinical trial ( ClinicalTrials.gov. NCT00633828) and conducted according to the Declaration of Helsinki.

Provenance and peer review Not commissioned; internally peer reviewed. Data sharing statement № additional data are available.

Open Access This is an Open Access article distributed in accordance with the Creative Commons Attribution Non Commercial (CC BY-NC 4.0) license, which permits others to distribute, remix, adapt, build upon this work non-commercially, and license their derivative works on different terms, provided the original work is properly cited and the use is non-commercial. See: http://creativecommons.org/ licenses/by-nc/4.0/

(c) Article author(s) (or their employer(s) unless otherwise stated in the text of the article) 2018. All rights reserved. No commercial use is permitted unless otherwise expressly granted.

\section{REFERENCES}

1. Sallis JF, Bull F, Guthold R, et al. Lancet Physical Activity Series 2 Executive Committee. Progress in physical activity over the Olympic quadrennium. Lancet 2016;388:1325-36.

2. Cöster ME, Rosengren BE, Karlsson C, et al. Effects of an 8-year childhood physical activity intervention on musculoskeletal gains and fracture risk. Bone 2016;93:139-45.

3. Mitchell JA, Pate RR, España-Romero V, et al. Moderate-to-vigorous physical activity is associated with decreases in body mass index from ages 9 to 15 years. Obesity 2013;21:E280-6.

4. Ericsson I, Karlsson MK. Motor skills and school performance in children with daily physical education in school-a 9-year intervention study. Scand J Med Sci Sports 2014;24:273-8.

5. Kavey RE, Daniels SR, Lauer RM, et al. American Heart Association. American Heart Association guidelines for primary prevention of atherosclerotic cardiovascular disease beginning in childhood. Circulation 2003;107:1562-6.

6. World Health Organization, (WHO). Global recommendations on physical activity for health. 2010. http://www.who.int/ dietphysicalactivity/publications/9789241599979/en/

7. Hallal PC, Andersen LB, Bull FC, et al. Lancet Physical Activity Series Working Group. Global physical activity levels: surveillance progress, pitfalls, and prospects. Lancet 2012;380:247-57.

8. Pate RR, Davis MG, Robinson TN, et al. American Heart Association Council on Nutrition, Physical Activity, and Metabolism (Physical Activity Committee)Council on Cardiovascular Disease in the YoungCouncil on Cardiovascular Nursing. Promoting physical activity in children and youth: a leadership role for schools: a scientific statement from the American Heart Association Council on Nutrition, Physical Activity, and Metabolism (Physical Activity Committee) in collaboration with the Councils on Cardiovascular Disease in the Young and Cardiovascular Nursing. Circulation 2006;114:1214-24.

9. Cronholm F, Rosengren BE, Karlsson C, et al. A physical activity intervention program in school is also accompanied by higher leisure-time physical activity: a prospective controlled 3-year study in 194 prepubertal children. J Phys Act Health 2017;14:301-7.

10. Sallis JF, McKenzie TL, Alcaraz JE, et al. The effects of a 2-year physical education program (SPARK) on physical activity and fitness in elementary school students. Sports, Play and Active Recreation for Kids. Am J Public Health 1997;87:1328-34.

11. Kriemler S, Zahner L, Schindler C, et al. Effect of school based physical activity programme (KISS) on fitness and adiposity in primary schoolchildren: cluster randomised controlled trial. BMJ 2010;340:c785.

12. Kelder SH, Mitchell PD, McKenzie TL, et al. Long-term implementation of the CATCH physical education program. Health Educ Behav 2003;30:463-75. 
13. Nader PR, Stone EJ, Lytle LA, et al. Three-year maintenance of improved diet and physical activity: the CATCH cohort. Child and Adolescent Trial for Cardiovascular Health. Arch Pediatr Adolesc Med 1999;153:695-704.

14. Anderson EL, Howe LD, Kipping RR, et al. Long-term effects of the Active for Life Year 5 (AFLY5) school-based cluster-randomised controlled trial. BMJ Open 2016;6:e010957.

15. Jurak G, Cooper A, Leskosek B, et al. Long-term effects of 4-year longitudinal school-based physical activity intervention on the physical fitness of children and youth during 7-year followup assessment. Cent Eur J Public Health 2013;21:190-5.

16. Raustorp A, Ekroth Y. Tracking of pedometer-determined physical activity: a 10-year follow-up study from adolescence to adulthood in Sweden. J Phys Act Health 2013;10:1186-92.

17. Meyer U, Schindler C, Zahner L, et al. Long-term effect of a schoolbased physical activity program (KISS) on fitness and adiposity in children: a cluster-randomized controlled trial. PLOS One 2014;9:e87929.

18. Raustorp A, Ekroth Y. Tracking of pedometer-determined physical activity: a 10-year follow-up study from adolescence to adulthood in Sweden. J Phys Act Health 2013;10:1186-92.

19. Telama R, Yang X, Leskinen E, et al. Tracking of physical activity from early childhood through youth into adulthood. Med Sci Sports Exerc 2014;46:955-62.

20. Gomersall SR, Maher C, English C, et al. Testing the activity stat hypothesis: a randomised controlled trial. BMC Public Health 2016;16:900.
21. Wilkin TJ, Mallam KM, Metcalf BS, et al. Variation in physical activity lies with the child, not his environment: evidence for an 'activitystat' in young children (EarlyBird 16). Int J Obes 2006;30:1050-5.

22. Frémeaux AE, Mallam KM, Metcalf $B S$, et al. The impact of schooltime activity on total physical activity: the activitystat hypothesis (EarlyBird 46). Int J Obes 2011;35:1277-83.

23. Marshall WA, Tanner JM. Variations in the pattern of pubertal changes in boys. Arch Dis Child 1970;45:13-23.

24. Marshall WA, Tanner JM. Variations in pattern of pubertal changes in girls. Arch Dis Child 1969;44:291-303.

25. Linden C, Ahlborg HG, Besjakov J, et al. A school curriculum-based exercise program increases bone mineral accrual and bone size in prepubertal girls: two-year data from the pediatric osteoporosis prevention (POP) study. J Bone Miner Res 2006;21:829-35.

26. Lindén $\mathrm{C}$, Alwis $\mathrm{G}$, Ahlborg $\mathrm{H}$, et al. Exercise, bone mass and bone size in prepubertal boys: one-year data from the pediatric osteoporosis prevention study. Scand J Med Sci Sports 2007:17:340-7.

27. Cliff DP, Hesketh KD, Vella SA, et al. Objectively measured sedentary behaviour and health and development in children and adolescents: systematic review and meta-analysis. Obes Rev 2016;17:330-44.

28. Sallis JF, Prochaska JJ, Taylor WC. A review of correlates of physical activity of children and adolescents. Med Sci Sports Exerc 2000;32:963-75

29. Sallis JF, Saelens BE. Assessment of physical activity by selfreport: status, limitations, and future directions. Res Q Exerc Sport 2000;71(Suppl 2):1-14. 